$\mathbb{T}$ periodica polytechnica

\author{
Transportation Engineering \\ $40 / 2(2012) 61 \quad 65$ \\ doi: 10.3311/pp.tr.2012-2.03 \\ web: http://www.pp.bme.hu/tr \\ (c) Periodica Polytechnica 2012
}

RESEARCH ARTICLE

\section{Determining and comparing the qualitative consistency of urban and highway traffic flows}

\author{
Gergely Gál
}

Received 2012-09-27

\begin{abstract}
Determining the traffic flows by considering not only the vehicle categories, but the greenhouse gas emission and the fuel consumption as well is an emerging problem of our days. However, only with static data about the vehicle fleet in a region, traffic flows cannot be characterized well enough. For a complex traffic control model the traffic flows considering the EURO emission standards have to be determined. To decide on the share between the different standards, the rolling vehicle fleet had to be recorded, and these dynamic data had to be analyzed for further research. Furthermore, this investigation was made in separate traffic conditions and on different infrastructures. The point of the paper is to determine the qualitative consistency both on urban and highway roads, and explore if there is a relationship between them.
\end{abstract}

\section{Keywords \\ emission · traffic flows · dynamic data}

\section{Introduction}

The CONTRA project aims to create a state of the art model for controlling traffic flows by taking into account economic aspects, namely cost calculation plays an important role in the management of transport companies [1]. To achieve this goal, the consistency of traffic flows has to be determined within the range of the regulation. In the first phase of the research the static data of the vehicle fleet was revealed, but it seemed that it does not characterize the rolling vehicle fleet well. So it was needed to validate these numbers with the actual rolling stock, thus in the second phase some measurements were made by recording the vehicles and classify them in EURO classes from EURO 1 to EURO 5. The comparison of the static and dynamic data is one of the main goals of this paper.

\section{The qualitative consistency of the vehicle fleet}

It is a rightful claim from the society to minimize the environmental impact of transportation and to develop transport infrastructure [2]. Transport is the second largest emitter of $\mathrm{CO}_{2}$ in the European Union, after the energy production sector, with a constantly increasing trend [3]. Whereas road transportation is the greatest polluter within the transportation sector [4]. Continued utilization of petroleum-based fuels is now widely recognized as unsustainable because of depleting supplies and contribution of these fuels to pollute the environment [5]. The reduction of $\mathrm{CO}_{2}$ emissions and fuel consumption from road transportation constitutes an important pillar of the European Union's strategy for implementing the Kyoto Protocol [6]. Thus reducing the emission can lead to social and individual benefits as well [7].

The analyzed static data originate from the year 2008. Fig. 1 shows, that in 2008 only one-third of the diesel cars were in the EURO 4 or higher environmental class. It means that two-third of the vehicles were quite pollutants and not so much environmentally friendly. The numbers show a worse picture in the field of petrol fuelled vehicles (see Fig. 22. In this category, only $20 \%$ of the total fleet were in the EURO 4 or higher environmental class, which means that $80 \%$ of the fleet were in the EURO 3 or worse environmental class.

The traffic flow of personal car movements together with the
Department of Transport Technology and Economics, BME,

Stoczek J. u. 2., H-1111 Budapest, Hungary

e-mail: galg@kgazd.bme.hu 


\section{Share of EURO standard categories by static diesel car fleet}

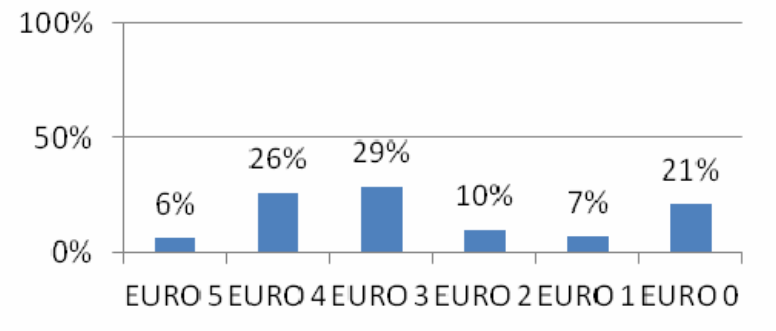

Fig. 1. Share of EURO standard categories by static diesel car fleet [8]

\section{Share of EURO standard categories by static petrol car fleet}

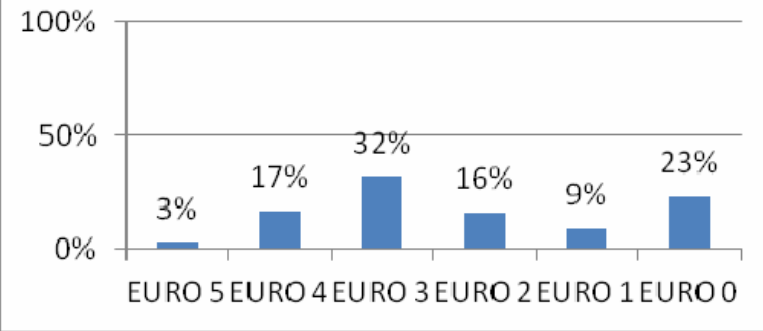

Fig. 2. Share of EURO standard categories by static petrol car fleet [8]

diffused flows of goods movements lead to transportation and logistics problem within urban areas. The frequency of freight movements became more intense in the past few years, which means that smaller trucks carry smaller cargo with worse capacity utilization. This causes many problems: congestions, longer travel times, more serious accidents, and negative environmental impacts. From the environmental impacts, air pollution is the greatest problem. For this reason, the share of freight vehicles in the field of air pollution and the locality where the pollutants are generated is to be identified.

Figure 3 illustrates that barely one-fourth of diesel trucks were in the EURO 4 or higher environmental class, and more than the three-fourth of the fleet were in less environmentally friendly classes. Figure 4 represents a more disappointing picture about petrol trucks. It shows that $95 \%$ of the fleet was EURO 3 or worse in 2008.

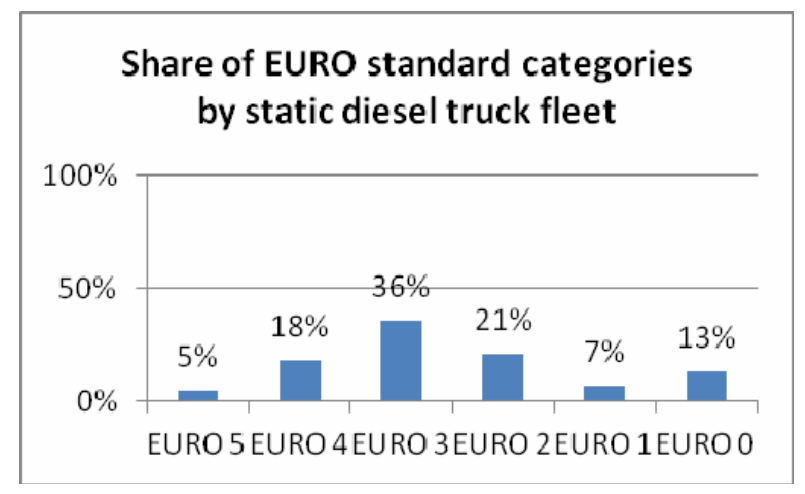

Fig. 3. Share of EURO standard categories by static diesel truck fleet [8]

\section{Share of EURO standard categories by static petrol truck fleet}

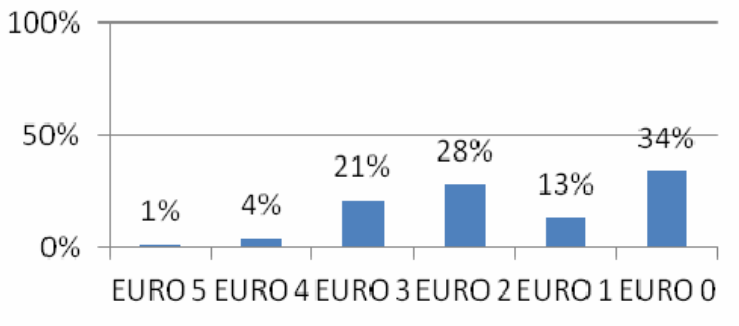

Fig. 4. Share of EURO standard categories by static petrol truck fleet 8

During the research, the relationship between static vehicle fleet data and dynamic traffic control model was successfully created with the revealed distribution values [9]. But the measurement for dynamic data was necessary to validate the model.

\section{The measuring method of urban and highway traffic flows}

The main goal of the measurement was to create a model, which can validate the static data originating from the vehicle fleet analyzes. Two kinds of measuring methods were used during the recording according to the location of the process. The urban part was set in seven road junctions, within and out of peak hours. Two persons were employed for manual measuring. One of them recognized and recorded the category of the vehicles, while the other checked the environmental plaque on the license plate number.

The recognized vehicle categories were the following:

- car

- light goods vehicle $(<3.5 \mathrm{t})$

- medium goods vehicle $(<7.5 \mathrm{t})$

- heavy goods vehicle $(>7.5 \mathrm{t})$

- bus

Table 1 represents the relationship between the environmental plaque and EURO standards according to Regulation 77/2009 (XII. 15.) KHEM-IRM-KvVM.

The highway part of the measurement was set on a highway flyover, using a license plate number recognition camera. As a result of this automatic recording, a huge number of license plate data were created. The license plate numbers were queried from the databank of the Central Office for Administrative and Electronic Public Services. The query provided the necessary environmental classification data for the analysis.

The measurements were made in the following places/junctions:

1 Teréz krt. - Andrássy út (Oktogon)

2 Múegyetem rkp. - Budafoki út

3 Múegyetem rkp. - Bertalan Lajos u. 
Tab. 1. Relationship between plaques and EURO standards

\begin{tabular}{|c|c|c|c|c|c|}
\hline Environmental class & EURO standard & Plaque & Environmental class & EURO standard & Plaque \\
\hline 0 & 0 & Black & 6 & 3 & Blue \\
\hline 1 & 0 & Black & 7 & 3 & Blue \\
\hline 2 & 0 & Red & 8 & 3 & Blue \\
\hline 3 & 1 & Black & 9 & 4 & Green \\
\hline 4 & 2 & Blue & 10 & 4 & Green \\
\hline \multirow{3}{*}{5} & \multirow{3}{*}{\multicolumn{2}{|c|}{ gas-, electric fuelled or hybrid }} & 11 & 4 & Green \\
\hline & & & 12 & 5 & Green \\
\hline & & & 13 & 5 & Green \\
\hline
\end{tabular}

4 Műegyetem rkp. - Egry József u.

5 Váci út - Róbert Károly krt.

6 Üllői út - József krt.

7 Thököly út - Hungária krt.

8 M7 Törökbálint - Széles u. highway flyover

The recording was set in good weather conditions on two days, on a Tuesday and on a Thursday. As a result of this measurement a large amount of data were created to compare the static and dynamic share of the vehicle fleet. The results shows that $71 \%$ of the traffic flows in these intersections were cars and $24 \%$ were light trucks. Only $3 \%$ of the total flow were medium goods vehicles, but it is significant that almost one-fourth of the traffic flow are diesel fuelled freight vehicles, which means a great threat because of the dust and solid particles.

Considering the EURO categories of the vehicle flow, it is declarable, that the half of the vehicles was EURO 3 or worse. Figure 5 represents that EURO 3 and EURO 4 categories give the two-third of the whole fleet. It means that the vehicle fleet cannot be categorized well with only the static data. The more environmentally friendly vehicles take a greater part in the traffic, as their share in static fleet data.

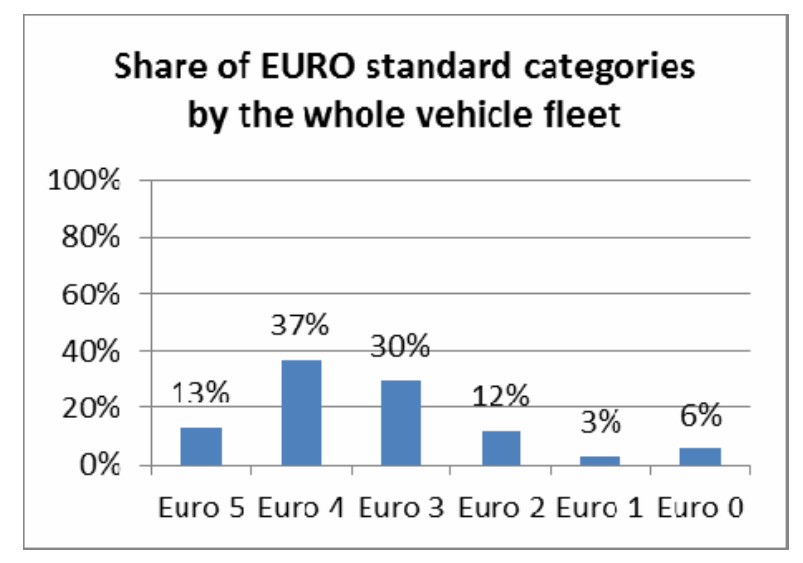

Fig. 5. Share of EURO standard categories by the whole vehicle fleet

\section{Comparison of static and dynamic data}

Figs. 6 to 9 show that there is a huge difference between static and dynamic vehicle fleet data. EURO 0 share within diesel cars dynamic data are significantly smaller than in static data.
However there is an opposite relation with EURO 4 and EURO 5 categories. It proves that the younger, less polluting vehicles have a greater mileage.

This tendency is more significant within the freight vehicle category, so the previous statement is proven in this case as well.

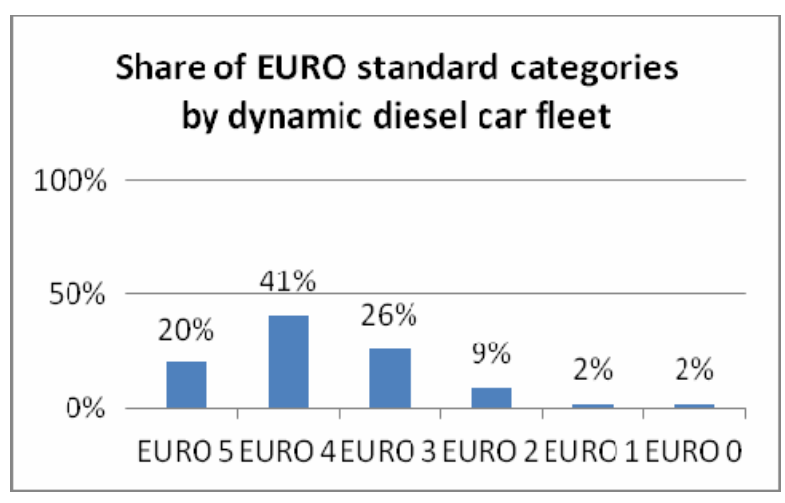

Fig. 6. Share of EURO standard categories by dynamic diesel car fleet

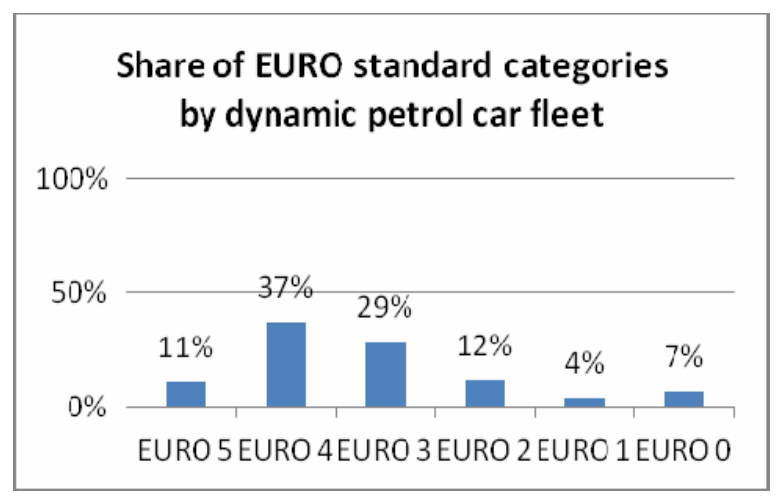

Fig. 7. Share of EURO standard categories by dynamic petrol car fleet

Figs. 10 to 13 show that there is a small difference between the share of EURO standard categories in urban roads and on highways. In urban areas EURO 3 categories are higher than on highways, however EURO 4 categories have a smaller share. Nevertheless the sum of these less pollutant categories is nearly equal, which means that the qualitative consistency of the rolling stock is similar, and the validation of the manual urban measurement was successful by the automatic license plate recognition system. 


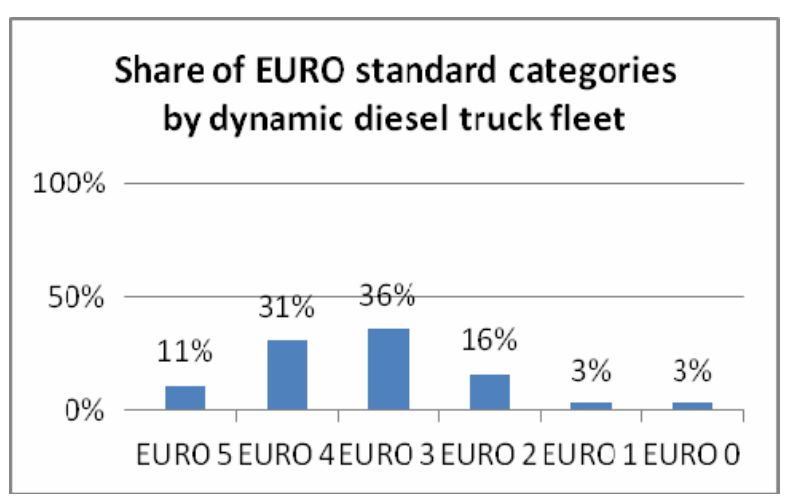

Fig. 8. Share of EURO standard categories by dynamic diesel truck fleet

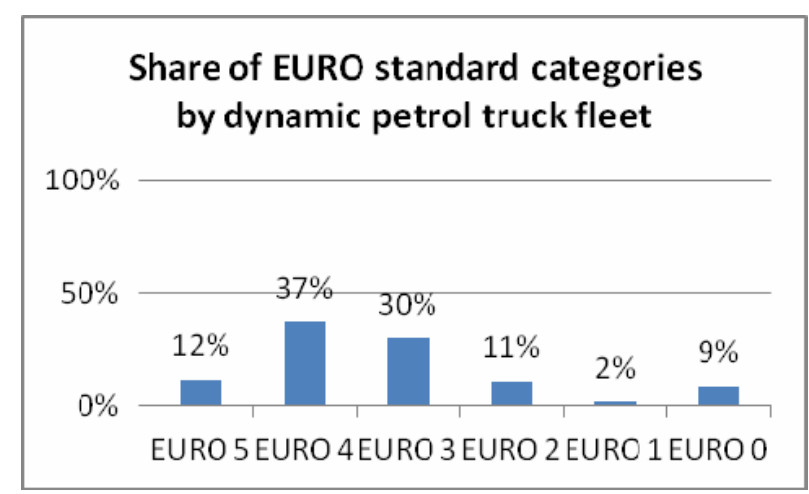

Fig. 9. Share of EURO standard categories by dynamic petrol truck fleet

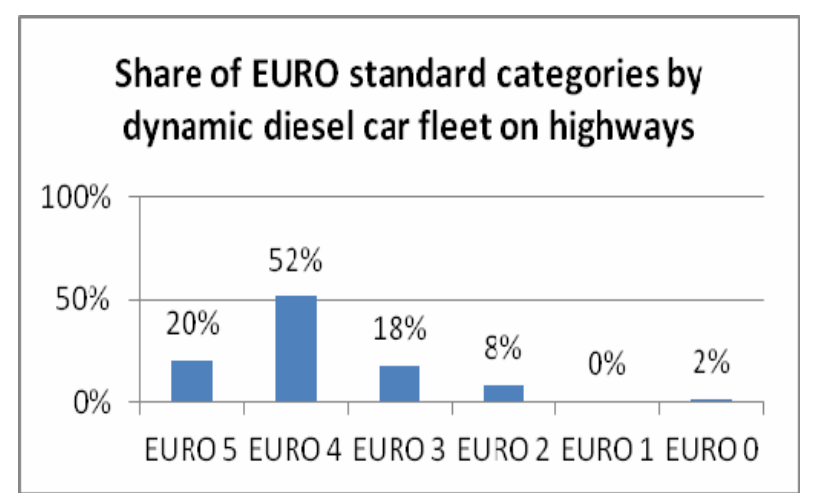

Fig. 10. Share of EURO standard categories by dynamic diesel car fleet on highways

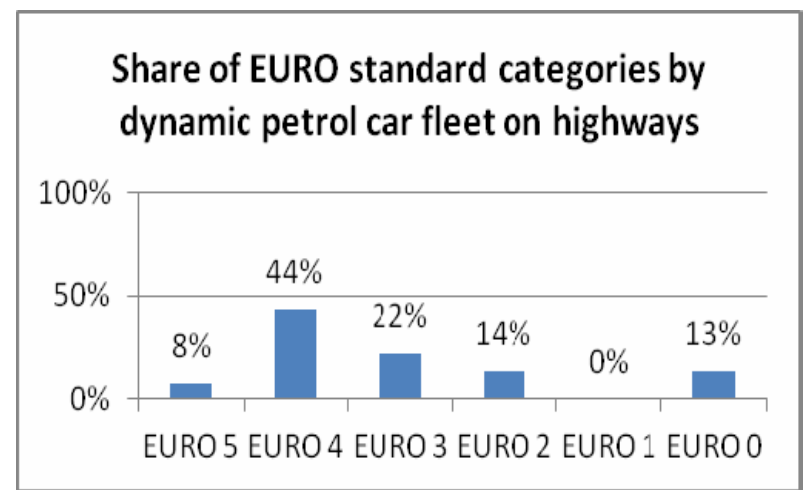

Fig. 11. Share of EURO standard categories by dynamic petrol car fleet on highways
Share of EURO standard categories by

dynamic diesel truck fleet on highways

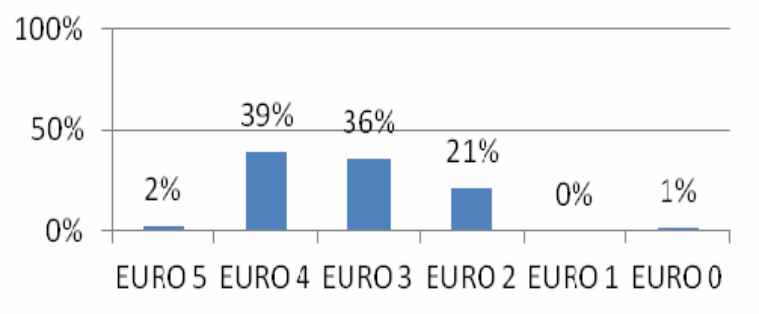

Fig. 12. Share of EURO standard categories by dynamic diesel truck fleet on highways

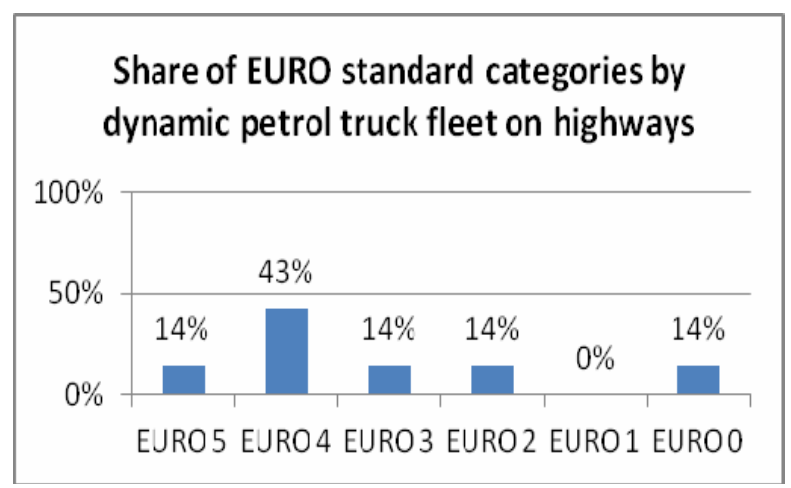

Fig. 13. Share of EURO standard categories by dynamic petrol truck fleet on highways

\section{Conclusion}

The traffic control model declared in the Contra project handles traffic flows, so it is very important to define the environmental impacts (emissions) of these flows. That was the reason of the vehicle fleet determination.

As a first step, we explored the static vehicle fleet database and in a second phase we validated it with a dynamic fleet measurement. As a result we established that the dynamic traffic flow is significantly different from the static vehicle fleet database, and the higher EURO categories are more common in the traffic than the more polluting categories, both in urban and in interurban traffic.

\section{Acknowledgement}

This work is connected to the scientific program of the "Development of quality-oriented and harmonized $\mathrm{R}+\mathrm{D}+\mathrm{I}$ strategy and functional model at BME" and "Modeling and multiobjective optimization based control of road traffic flow considering social and economical aspects" project. These projects are supported by the New Széchenyi Plan (Project ID: TÁMOP4.2.1/B-09/1/KMR-2010-0002) and by program CNK 78168 of OTKA.

\section{References}

1 Bokor Z, Calculation model for transport costing, Periodica Polytechnica Transportation Engineering 39 (2011), no. 1, 43-47, DOI 10.3311/pp.tr.2011-1.08. 
2 Bokor Z, Duma L, Sustainable mobility - environmental friendly transportation modes (Pethő E, ed.), OMIKK, Budapest, 1999.

3 Bampatsou C, Zervas E, Critique of the regulatory limitations of exhaust $\mathrm{CO}_{2}$ emissions from passenger cars in European union, Energy Policy 39 (December 2011), 7794-7802, DOI 10.1016/j.enpol.2011.09.024.

4 Mészáros F, Expected impacts of the development of national road transportation on energy consumption and environment, Environment and Energy Conference. Debrecen, Hungary, 2009.05.08-2009.05.09. Debrecen: MTA DAB renewable Energetic Working Committee.

5 Bereczky Á, Török Á, International literature review on the possibilities of biodiesel production, Periodica Polytechnica Transportation Engineering 39 (2011), 31-37, DOI 10.3311/pp.tr.2011-1.06.

6 Fontaras G, Samaras Z, A quantitative analysis of the European Automakers' voluntary commitment to reduce $\mathrm{CO}_{2}$ emissions from new passenger cars based on independent experimental data, Energy Policy 35 (April 2007), 2239-2248, DOI 10.1016/j.enpol.2006.07.012.

7 Török Á, Zöldy M, Energetic and economical investigation of greenhouse gas emission of Hungarian road transport sector, Pollack Periodica: An International Journal for Engineering and Information Sciences 5 (2010), 123132, DOI 10.1556/Pollack.5.2010.3.10.

8 Varga R, Kibedi-Varga L, Markovits-Somogyi R, Török Á, Mészáros F, Statistical Assessment of traffic quality in Budapest, Toyotarity: Knowledge using in production management (Borkowski S, Nabialek M, eds.), Dnepropetrovsk: Yurii V Makovetsky, 2010.

9 Mészáros F, Markovits-Somogyi R, Bokor Z, Modelling and multicriteria optimization of road traffic flows considering social and economic aspects, Scientific Journal on Transport and Logistics 3 (2012), 70-82. 